\title{
Prevalence of Unsatisfactory Pap Smear and Associated Clinical History and Diagnosis in a Tertiary Teaching Hospital in Ghana
}

\author{
Maxwell Hubert Antwi ${ }^{1}$, Seth Christopher Yaw Appiah ${ }^{2,3}$ (1) \\ ${ }^{1}$ Department of Molecular Medicine, School of Medical Sciences, College of Health Sciences, Kwame Nkrumah \\ University of Science \& Technology, Kumasi, Ghana; ${ }^{2}$ Department of Sociology and Social Work, Faculty of \\ Humanities and Social Sciences, Kwame Nkrumah University of Science and Technology, Kumasi, Ghana; \\ ${ }^{3}$ Centre for International Health (CIH), University of Munich Medical School, Ludwig-Maximilians-Universitate \\ of Munchen, Munchen, Germany
}

Correspondence to: Seth Christopher Yaw Appiah, sychrist2007@gmail.com Keywords: Pap Smear, Unsatisfactory, Bethesda System, Malignancy, Ghana Received: March 12, 2019 Accepted: June 8, 2019 Published: June 11, 2019

Copyright $\odot 2019$ by authors and Scientific Research Publishing Inc.

This work is licensed under the Creative Commons Attribution International License (CC BY 4.0).

http://creativecommons.org/licenses/by/4.0/

(c) (i) Open Access

\section{ABSTRACT}

Background: A major limitation of cervical cytology is the unsuitability of proportion of smears submitted for analysis and for cytological assessment (unsatisfactory). This study examines the prevalence of unsatisfactory Pap smear, clinical history and diagnosis in the Department of Pathology, Korle-Bu Teaching Hospital (KBTH), Ghana. Materials and Methods: A retrospective review of 15,290 cases spanning 12 years (2005-2016) was carried out at the cytology unit of the Pathology Department of the KBTH. Out of the 15,290 Pap smear records retrieved, 2347 reports were excluded leaving 12,943 for the study. All unsatisfactory smear cases were analyzed and categorized using the Bethesda 2001 System. Results are presented using descriptive statistics. Results: The overall prevalence of unsatisfactory Pap smear was 402 (3.1\%). Routine screening smear accounted for 115 (0.9\%); reports without clinical history and diagnosis gave $21(0.2 \%)$ and cases with clinical history and diagnosis were 287 (2.2\%). The common cause of unsatisfactory Pap smear was scanty cellularity 222 (1.72\%). Patient's history accounted for the least cause of unsatisfactory Pap smear 2 $(0.02 \%)$. Conclusion: Pap smear results reported as unsatisfactory could harbor cancer malignancy. Samples should be taken by well-trained persons.

\section{INTRODUCTION}

Cancer is a global health concern. Millions of individuals have been diagnosed and several affected 
people have lost their lives. Cancer of the uterine cervix is a leading public health issue globally and is the commonest cancer in the female genital tract $[1,2]$. Over the past two decades, the incidence of the disease has shown a decline in the developed countries [3,4], yet in poor resource settings like Ghana, there has not been significant change in both prevalence and incidence. $[1,5]$

A report by Ghana health service rated cervical cancer as the topmost cancer affecting women in Ghana, and attributed 50.5\% of the condition to human papillomavirus (HPV) types 16 and 18 with $16 \%$ as cause of death attributable to cancer [6].

Estimates by the World Health Organization (WHO) posit that cervical cancer case in Ghana will exceed 5000 with mortality of 3300 annually by 2025 if the trend persists [7]. It has become difficult to relegate the condition in the country to the background without attention. Larger percentage of women of reproductive age stand at increased risk of having cancer of the uterine cervix since there is no national screening programme or management readily available $[6,8]$.

Screening of cervical cancer is uncommon in Ghana as the test is done in few public and private health centers in the country and is lowly patronized by the target group (women) $[8,9]$. Nevertheless, risk of dying from cervical cancer can be reduced with routine Pap test $[1,4]$. It has been reported that, the annual global death rates attributable to cervical cancer has declined by $2 \%$ ever since Pap smear test was introduced with overall death rate by $74 \%$ [10].

The Pap test results indicate various changes relating to clinical observation such as; unsatisfactory, normal, inflammation, benign cellular changes, Atypical Squamous cell of undetermined significance (ASCUS), High Grade Squamous Intraepithelial Lesion (HGSIL) and cervical cancer $[2,11]$. Despite its outstanding success, the Pap smear is not $100 \%$ perfectly accurate [12-14]. Problems occur at every level from failure of women to get regular Pap smear test in the first place to sampling and interpretation error which is likely to give unsatisfactory results that would need a clinical follow-up [12-14].

The number of false negative reports is of great concern because some are reported as a result of unsatisfactoriness $[2,15]$. One of the limitations of cervical cytology is that a proportion of smears submitted for analysis in the light microscope are unsuitable for reliable cytological assessment $(3,4)$. This category of limitation is considered as unsatisfactory Pap smears [11]. Pap smear according to the Bethseda system can be categorized as follows; Sampling error; this error can be due to slide lacking an adequate number of well-preserved and well-visualized squamous epithelial cells (minimum of 8000 - 12,000 for conventional Pap or 5000 for Liquid-base pap, thus scanty cellularity) $[11,14]$.

Processing error includes poor fixation, air-drying artifact or contaminants obscuring over $75 \%$ of the epithelial cells and cellular material being too thick or multilayering smear [11, 14]. Obscuring error includes cells being too atrophic, blood and inflammation obscuring over $75 \%$ of the epithelial cells, excessive cytolysis $[11,14]$. A broken slide which affects smear for cytologic examination is technically unaccepted. Lack of pertinent patient information and clinical history are as cause of unsatisfactory Pap smear. Any of the causes under these errors can be unsatisfactory.

A large prospective study done in Norway found that unsatisfactory Pap smear test results indicated a 1.6 to 4.0 times high risk of harbouring CIN $2 / 3$ or invasive cervical cancer compared with woman with a normal Pap test result [16]. Unsatisfactory category constitutes $1 \%$ to $2 \%$ of all Pap test [17-19]. There are however little information and knowledge on its prevalence in Ghana and particularly at the nation's biggest teaching hospital, Korle-Bu Teaching Hospital.

The essence of this study was to provide adequate data and knowledge on unsatisfactory Pap smears' prevalence and causes in line with their respective clinical history and diagnosis and to help health-care practitioners with measures to minimize any error that could lead to unsatisfactory Pap smear. This study provides baseline data for comparison with similar reviews in future since there is currently no known scientific documented evidence on unsatisfactory Pap smear prevalence in Ghana.

\section{METHODS}

\subsection{Setting}

The study was conducted at the Korle-Bu Teaching hospital. The hospital is the largest health facility 
and also the premier teaching hospital in Ghana. The Korle-Bu Teaching hospital has a bed capacity of over 2000 and offering medical training for medical doctors, nurses and other health professionals. There are 17 clinical and diagnostic departments/units in the hospital. The hospital is host to the National Centre for Radiotherapy and Nuclear Medicine which functions as a referral centre for the management of cancer supporting other specialized services such as renal transplantation, DNA investigations and brachy therapy for the treatment of prostate cancer. The study was carried out using data from the cytology unit of the Pathology Department of the KBTH.

\subsection{Study Design and Sampling}

The study was retrospective review of all Pap smear registry data of women who underwent Pap smear at the cytology unit of the Korle-Bu hospital spanning a period of 12 years (2005-2016). The study used a hospital based registry which has a catchment that covers the entire southern part of Ghana and beyond without any well-defined population. However, under the period the studied, 15,290 conventional Pap smear test reports were retrieved. The cytology unit actively collects data on all Pap smear cases presenting to the hospital for possible diagnosis of cervical cancer. The data sources are often from either women regular visits to the various clinics and wards of admission or by referral to the unit from within the hospital or outside the hospital. A special case folder is created (folders) within the unit to abstract needed information with succinct case definition. Information on the clinical history of patients was extracted from the medical folders of each client through a careful sifting of the records.

\subsection{Analysis}

The reports taken from the archives had their covers cleaned and the total Pap smear reports were noted as 15,290. Out of the 15,290 reports, 2347 (both missing reports and lack of TZ components reports) were excluded so 12,943 reports were left for the study. The criteria for the unsatisfactory diagnosis were according to the Bethesda System 2001 and their causes categorized as; sampling error due to inadequate number of well preserved and well visualized squamous epithelial cells (minimum of $8000-12,000$ for conventional Pap smear) - thus scant cellularity ( $<10 \%$ of slide covered by interpretable squamous cells), processing error due to poor fixation, air-drying artifact or contaminants obscuring over $75 \%$ of the epithelial cells and cellular material too thick or multilayering smear, presence of obscuring error of the test due to cells being too atrophic with blood and or inflammation obscuring over $75 \%$ of the epithelial cells, excessive cytolysis, broken slide, and lack of patient's history. The 12,943 reports were reviewed for unsatisfactory diagnosis in line with their respective clinical history and diagnosis viz. age, and their causes were noted, counted and grouped into the various categories. The frequencies of the various categories and what constitute them were determined. The prevalence of the unsatisfactory Pap smears in percentages annually were determined and the overall prevalence within that time frame was also known. The prevalence in percentage was calculated as; (total unsatisfactory Pap smears/total Pap smears) multiply by 100. The data was exported into Microsoft Excel and SPSS version 16 for windows and further analysis. Ethics approval was sought from the University of Ghana Ethics approval committee

\section{RESULTS}

\subsection{Population Characteristics}

A total number of Pap smears and smears rejected as unsatisfactory reviewed over the twelve year period (Table 1). A total of 15,290 conventional Pap smear test reports were retrieved for review from the archives at the cytology unit of the department of pathology, KBTH over a twelve-year period. Out of the 15,290 Pap smears reports, 529 were missing in the archives, 1818 were limited by lack of transformation zone component and so both (2347 reports) were excluded from this study. The entire Pap smear reports for 2011 could not be found from archives and were excluded.

The total Pap smear over the period was 12,943 and unsatisfactory Pap smear was also 402. The aver- 
age age and age range of women who attended the unit to do Pap smear test were 39.5 and 19 - 80 years respectively. Smears rejected as unsatisfactory were assessed in line with their respective clinical history and diagnosis and their percentages recorded as follows. Unsatisfactory rate with history as routine screening was $115(0.9 \%)$, with clinical history and diagnosis was $287(2.2 \%)$, rate in reports without clinical diagnosis gave $21(0.2 \%)$ and the overall rate in all diagnosis and routine screening was $402(3.1 \%)$.

\subsection{Causes of Unsatisfactory Pap Smear and Associated Diagnosis and Clinical History}

Table 2 shows the various causes of unsatisfactory Pap smears in line with clinical history and diagnosis. Scanty cellularity $77(0.6 \%)$ gave higher number for almost all the clinical history and diagnosis with routine screening. This was followed by uterine fibroid $52(0.4 \%)$, infertility $27(0.2 \%)$ (amenorrhea, dysmenorrhea, menorrhagia, dysuria, leiomyoma), cancer 20 (0.2\%) (cervical cancer, endometrial cancer). Accordingly, the least factors that accounted for the unsatisfactory Pap smear were post-menopausal bleeding, bleeding in urine) and cytolysis $2(0.02 \%)$

\subsection{Cause Specific Categorization of Unsatisfactory Pap Smear}

The results presented in Table 3 show the frequency and annual percentages of the unsatisfactory categories based on their causes. The total and annual percentages of the unsatisfactory categories were presented according to each year. In 2005, total unsatisfactory Pap smear was 63 (4.2\%), 2006 presented 23 (3.7\%), 2007 gave 54 (5.3\%), 2008 was 38 (3.7\%), 2009 gave $38(2.9 \%), 2010$ was $47(3.7 \%), 2012$ gave 33 (2.7\%), 2013 was 39 (2.8\%), 2014 gave 40 (2.5\%), 2015 was $16(1.2 \%), 2016$ gave $11(1.6 \%)$ and the overall annual percentage was $402(3.1 \%)$.

The unsatisfactory categories based on their causes were reported. Sampling error gave total unsatisfactory rate of $222(1.72 \%)$, processing error gave $46(0.36 \%)$, inherent error of the test was $132(1.02 \%)$ and patient history was $2(0.02 \%)$.

\subsection{Year to Cause Categorization of Unsatisfactory Pap Smear}

Table 4 shows the various categorization of unsatisfactory Pap smear. Scanty cellularity was the highest recording $222(1.72 \%)$ followed by obscured inflammation $69(0.53 \%)$, blood obscurance $56(0.43 \%)$, thick smear $17(0.13 \%)$, with the east being cytolysis 7 (0.05\%) and patient history $2(0.02 \%)$.

\section{Table 1 . Study population characteristics.}

\begin{tabular}{ll}
\hline Data & $\mathrm{N}(\%)$ \\
\hline Actual number of conventional Pap smear retrieved & $1520(100 \%)$ \\
Missing cases in the Archive & $529(3.5 \%)$ \\
Pap smear data limited by transformation zone component & $1818(10.9 \%)$ \\
Total number of Pap smears reviewed & 12,943 \\
Total unsatisfactory Pap smears reviewed & 401 \\
Age of women (range) years & $9-80 \mathrm{yrs}$ \\
Mean age (yrs) & 39.5 \\
Unsatisfactory rate in routine screening & $115(0.9 \%)$ \\
Unsatisfactory rate in clinical history and diagnosis & $287(2.2 \%)$ \\
Unsatisfactory rate in reports without clinical diagnosis & $21(0.2 \%)$ \\
Unsatisfactory rate in all diagnosis and routine screening & $402(3.1 \%)$ \\
\hline
\end{tabular}


Table 2. Causes of unsatisfactory Pap smear and associated diagnosis and clinical history.

\begin{tabular}{llllllllll}
\hline \multirow{2}{*}{$\begin{array}{l}\text { Reason for } \\
\text { unsatisfactory }\end{array}$} & $\begin{array}{l}\text { R linical History and Diagnosis } \\
\text { RS No }\end{array}$ & ND No. & \multicolumn{2}{l}{ UF No. Hys/Myo Inf No. } & Ca & PB No. & \multicolumn{2}{l}{ Total } \\
& $\%$ & $\%$ & $\%$ & $\%$ & $\%$ & $\%$ & $\%$ & \\
\hline $\begin{array}{l}\text { Scanty cells } \\
\text { Obscuring }\end{array}$ & $77(0.6)$ & $11(0.08)$ & $52(0.4)$ & $20(0.2)$ & $27(0.2)$ & $20(0.2)$ & $15(0.1)$ & $222(1.7)$ \\
inflammation & $18(0.1)$ & $4(0.03)$ & $3(0.02)$ & $17(0.1)$ & $7(0.05)$ & $11(0.08)$ & $9(0.07)$ & $69(0.5)$ \\
Obscuring blood $10(0.08)$ & $2(0.02)$ & $4(0.03)$ & $4(0.03)$ & $11(0.08)$ & $12(0.09)$ & $13(0.1)$ & $56(0.4)$ \\
Thick smear & $4(0.03)$ & $1(0.01)$ & $2(0.02)$ & $3(0.02)$ & $3(0.02)$ & $1(0.01)$ & $3(0.02)$ & $17(0.1)$ \\
Drying artifact & $3(0.02)$ & $1(0.01)$ & $3(0.02)$ & $2(0.02)$ & $2(0.02)$ & $2(0.02)$ & $2(0.02)$ & $15(0.1)$ \\
Poor fixation & $1(0.01)$ & $2(0.02)$ & $3(0.02)$ & $3(0.02)$ & $2(0.02)$ & $1(0.01)$ & $2(0.02)$ & $14(0.1)$ \\
Cytolysis & $2(0.02)$ & 0 & $1(0.01)$ & $1(0.01)$ & $1(0.01)$ & $1(0.01)$ & $1(0.01)$ & $7(0.05)$
\end{tabular}

RS-Routine screening, ND-No diagnosis, UF-Uterine fibroid, Hys/Myo-Hysterectomy/Myomectomy, Inf-Infertility (amenorrhea, dysmenorrhea, menorrhagia, dysuria, leiomyoma), Ca-(cervical cancer, Endometiral cancer), PB-(Post coital bleeding, Post-menopausal bleeding, bleeding in urine).

Table 3. Categorization of unsatisfactory Pap smear based on their causes.

\begin{tabular}{ccccccccc}
\hline Years & $\begin{array}{c}\text { Samplin g } \\
\text { error }\end{array}$ & $\begin{array}{c}\text { Processin g } \\
\text { error }\end{array}$ & $\begin{array}{c}\text { Inherent error } \\
\text { of the test }\end{array}$ & $\begin{array}{c}\text { Patient } \\
\text { history }\end{array}$ & $\begin{array}{c}\text { Broken } \\
\text { slide }\end{array}$ & $\begin{array}{c}\text { Total Unsat. } \\
\text { Pap smears }\end{array}$ & $\begin{array}{c}\text { Total Pap } \\
\text { smears }\end{array}$ & $\%$ \\
\hline 2005 & 34 & 8 & 21 & 0 & 0 & 63 & 1488 & 4.2 \\
2006 & 14 & 1 & 8 & 0 & 0 & 23 & 621 & 3.7 \\
2007 & 35 & 9 & 9 & 1 & 0 & 54 & 1011 & 5.3 \\
2008 & 26 & 4 & 8 & 0 & 0 & 38 & 1023 & 3.7 \\
2009 & 25 & 3 & 9 & 1 & 0 & 38 & 1298 & 2.9 \\
2010 & 35 & 3 & 9 & 0 & 0 & 47 & 1274 & 3.7 \\
2012 & 13 & 4 & 16 & 0 & 0 & 33 & 1215 & 2.7 \\
2013 & 17 & 9 & 13 & 0 & 0 & 39 & 1382 & 2.8 \\
2014 & 14 & 5 & 21 & 0 & 0 & 40 & 1594 & 2.5 \\
2015 & 6 & 0 & 10 & 0 & 0 & 16 & 1336 & 1.2 \\
2016 & 3 & 0 & 8 & 0 & 0 & 11 & 701 & 1.6 \\
& 222 & 46 & 132 & 2 & 0 & 402 & 12943 & 3.1 \\
Total \% & 1.72 & 0.36 & 1.02 & 0.02 & 0.00 & 3.12 & - & - \\
\hline
\end{tabular}

Table 4. Year-to year causes and categorization of unsatisfactory Pap smear.

\begin{tabular}{lcccccccccc}
\hline Years & $\begin{array}{c}\text { Scant } \\
\text { cellularity }\end{array}$ & $\begin{array}{c}\text { Thick } \\
\text { smear }\end{array}$ & $\begin{array}{c}\text { Poor } \\
\text { fixation }\end{array}$ & $\begin{array}{c}\text { Air- } \\
\text { drying }\end{array}$ & $\begin{array}{c}\text { Blood } \\
\text { obscure }\end{array}$ & Cytolysis & $\begin{array}{c}\text { Obscured } \\
\text { inflammation }\end{array}$ & $\begin{array}{c}\text { Patient } \\
\text { history }\end{array}$ & $\begin{array}{c}\text { Broken } \\
\text { slide }\end{array}$ & $\begin{array}{c}\text { Total } \\
\text { Unsat pap }\end{array}$ \\
\hline 2005 & 34 & 0 & 5 & 3 & 8 & 2 & 11 & 0 & 0 & 63 \\
2006 & 14 & 0 & 1 & 0 & 1 & 0 & 7 & 0 & 0 & 23 \\
2007 & 35 & 5 & 1 & 3 & 5 & 2 & 2 & 1 & 0 & 54 \\
\hline
\end{tabular}




\section{Continued}

\begin{tabular}{|c|c|c|c|c|c|c|c|c|c|c|}
\hline 2008 & 26 & 2 & 1 & 1 & 6 & 0 & 2 & 0 & 0 & 38 \\
\hline 2009 & 25 & 2 & 1 & 0 & 5 & 0 & 4 & 1 & 0 & 38 \\
\hline 2010 & 35 & 0 & 0 & 3 & 5 & 0 & 4 & 0 & 0 & 47 \\
\hline 2012 & 13 & 3 & 0 & 1 & 3 & 1 & 12 & 0 & 0 & 33 \\
\hline 2013 & 17 & 1 & 5 & 3 & 5 & 0 & 8 & 0 & 0 & 39 \\
\hline 2014 & 14 & 4 & 0 & 1 & 13 & 0 & 8 & 0 & 0 & 40 \\
\hline 2015 & 6 & 0 & 0 & 0 & 2 & 2 & 6 & 0 & 0 & 16 \\
\hline 2016 & 3 & 0 & 0 & 0 & 3 & 0 & 5 & 0 & 0 & 11 \\
\hline Total & 222 & 17 & 14 & 15 & 56 & 7 & 69 & 2 & 0 & 402 \\
\hline \multicolumn{11}{|c|}{ Total Pap Smears 12943} \\
\hline$\%$ & 1.72 & 0.13 & 0.11 & 0.12 & 0.43 & 0.05 & 0.53 & 0.02 & 0 & 3.1 \\
\hline
\end{tabular}

\subsection{Prevalence to Year Specific Rates of Unsatisfactory Pap Smear}

The graph presented in Figure 1 shows that over the years, the highest number of sampling error cases was recorded in 2007 with $35(5.3 \%)$ cases. Highest processing error related cases were recorded in the years 2007 and $2013(\mathrm{n}=9)$. No case of broken slide was recorded during the 12 years period. Despite the decline in recorded cases resulting from inherent error of the test from 21 cases in 2005 to a stable 8 and 9 recorded cases over a five year period up to 2010, it increased again in 2012 to 16 recorded cases, fell to 13, increased again to 21 in 2014 and begun to record lower cases in the last two years preceding the end point year for this study (2016).

\section{DISCUSSION}

The purpose of this study was to determine the prevalence of unsatisfactory Pap smear in the department of pathology, KBTH and to know the various causes in line with their respective clinical history and diagnosis. The overall prevalence of unsatisfactory Pap smear in this study was 3.1 percent. This estimate is lower when compared to reports from studies done in India, Italy and Taiwan but on the rise when compared to previous studies by Ransdell et al., McGaraghan and Smith-McCune in United States and Netherlands [17, 19-22]. Though the annual prevalence of unsatisfactory Pap smear demonstrates no consistent pattern, year on year prevalence appears to be on the decline. From the annual prevalence in percentages of the unsatisfactory Pap smears, the year 2007 recorded the highest prevalence of 5.3 percent. There was however no suggestive trend or pattern to conclude that the higher the total number of Pap smears or unsatisfactory Pap smear, the higher the prevalence in percentage of unsatisfactory Pap smear to demonstrate any association.

Despite, the study's inability to determine specific cause attribution to the Pap smear decline, the increasing training and clinical experiences of laboratory scientist at the Cytology Unit of the Korle-Bu Teaching Hospital (KBTH) might play a role.

Though the current study had a lower rate of unsatisfactory Pap smears compared to previously reported findings in India, Italy and Taiwan, the rate (3.1\%) remains high because unsatisfactory Pap smear rate of all categories according to reference books should be between $1 \%$ to $2 \%$ This is against the background that longitudinal studies of women with unsatisfactory Pap tests have reported an increased risk of epithelial abnormalities $[18,23]$. The higher prevalence could be attributed to the conventional approach of Pap smear preparation done at the department but not the liquid-base technology that is able to significantly reduce unsatisfactory rate $[14,24]$ at the time of the data period. The common reason for unsatisfactory Pap smear in this study was scanty cellularity followed by obscuring inflammation and blood. Scanty cellularity as a cause of unsatisfactory Pap smear has been confirmed in previous studies [17, 20, 23]. It is not surprising to emerge as the most common cause of unsatisfactory Pap smear. 


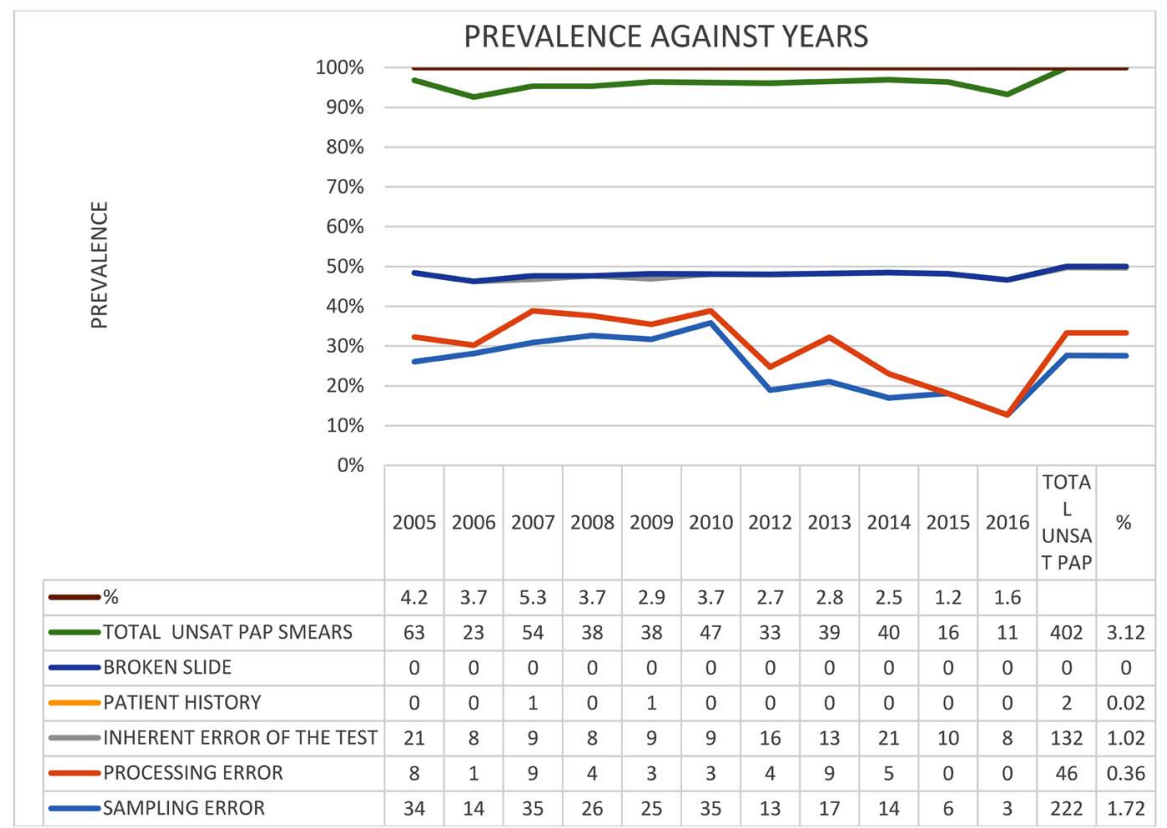

Figure 1. A line plot of graph of unsatisfactory Pap smear prevalence against annual years.

The increasing contribution of scanty cellularity to unsatisfactory Pap smear rates may be explained within the context of its relationship with the technique of sampling. Thus, sample taking by well-trained persons might contribute to reducing the overall rate of unsatisfactory Pap smear. In the current study, though lack of Transformation Zone components in a smear was not considered as unsatisfactory, it is related to sampling technique giving about 1818 excluded reports in this study. The type of sampling device used can also influence specimen adequacy and smear quality (thus present of TZ components) and necessitating the adoption of proper sampling device is encouraged $[3,25]$. As reported in previous studies elsewhere [3], scraping the cervix with the extended tip of the spatula followed by using a cytobrush gives adequate samples far better results $[3,25]$.

Adopting this approach will be key to enhancing the quality of the sampling. In terms of frequency in the current study, obscuring inflammation and blood were the next most frequent causes of unsatisfactory Pap smear and were related to the obscuring error of the test. Consistent with previously studies by McGaraghan and Smith-McCune in 2000 and by Owens and colleagues in 2013, Obscurance by blood or inflammation as a cause of unsatisfactory Pap smear $[14,20]$ results from obscuring error of the test. It is the recognition of this error that led to the bringing on board of the liquid-based sampling method that is able to correct the anomaly and generally decreases obscuring problems [24].

This current study had significant rate from this error because, the department of cytology still uses the conventional method of Pap smear preparation. Improved patient preparation or clinician technique (thus not sampling during the patient's menstrual period) may correct or reduce this cause of the unsatisfactory by obscured Pap $[12,26]$. Beyond improving patient preparation, careful attention to transferring of cells onto slide (thus smear preparation), immediate and proper fixation can address thick smear and air-drying problems $[3,25]$ since these contributed to the causes of unsatisfactory Pap smear under processing error in this study. Better processing of Pap smears therefore yields quality or satisfactory smears for cytological diagnosis $[3,25]$.

In our present study, patient's history was labeled as unsatisfactory though the number was not high. Care should be taken to avoid such clerical mistakes. There is little extensive data on how patient history accounts for unsatisfactory Pap smear. However, we found patient history potentially resulting from clerical errors to be responsible for $2(0.02 \%)$ cases of unsatisfactory Pap smear, a development which rarely 
occurs. None was labeled as unsatisfactory due to technically broken slide and this quality of handling of Pap smear slides should be maintained.

Following a classical definition of unsatisfactory Pap smear as an unreliability in the detection of cervical epithelial abnormalities $[18,27]$, the definition is relevant in patient management especially within the context of this studies and its findings.

As suggested in previous studies, considering unsatisfactory Pap smears as negative is problematic since negative means absence of disease (SIL or malignancy) and may not prompt adequate follow-up measures $[17,24]$. Evidence exists on the possible outcomes when unsatisfactory Pap smears are considered as negative because strong association between false-negatives and unsatisfactory specimens has been amply documented in retrospective studies $[17,18]$. Thus, a clear operational definition would need to comply with, for which clinical significance of such smears would need to be determined as well.

The recommended management for unsatisfactory Pap test is to repeat within 2 to 4 months, but this is hardly done in the present study setting due to the patient's inability to comply usually resulting in missed screening for these women. Similar observations have been reported in low resource settings particularly in different parts of Ghana where infrequent screening opportunities $[8,9]$ exist. Due to the difficulty with the management of unsatisfactory Pap smear, some studies have posited the need for re-screening though re-screening of previous false-negative Pap smears in patients with current CIN 3 and cancer appears difficult in resource limited settings [13]. Notwithstanding, Davey and others study are reassuring in terms of how retrospective re-screening of previously false-negative patients with current CIN 3 and cancer was proven be unsatisfactory after review [13], a finding consistent with earlier studies [16-18]. This calls for the urgent need to have repeated screening whiles minimizing the quick disposition to consider screening results as false-negative.

Unsatisfactory causes were also reviewed in line with their respective clinical history and diagnosis for which unsatisfactory rate from routine screening accounted for $0.86 \%$, whilst and unsatisfactory rate in reports without diagnosis and clinical history was $0.17 \%$.

The clinical history and diagnosis is mostly the primary reason propelling women to do Pap smear in the study setting. The indications as reflected in this current study suggest that patronage by women to do medical check-up for Pap smear is not on the rise because possible predictions could be made from such perspective on the number of women who do Pap smear screening. Mostly, sampling from women with clinical history and diagnosis of any kind especially malignancy and some benign is a bit challenging and could lead to unsatisfactory smear. This observation carries some veracity particularly when it has been established that additional clinical evaluation, thus inflammation and bleeding associated with CIN $3 /$ carcinoma and some benign cases may cause partially obscured or unsatisfactory Pap tests [16] despite the suggested guidelines $[13,16,28]$ on having additional clinical evaluation on women with symptoms and abnormal physical findings [16]. The adoption of continuous quality improvement measures and giving of feedback on quality indicators is critical to decreasing unsatisfactory Pap smears as it has been confirmed in different settings so that CIN $2 / 3$ and invasive carcinoma, are not harboured $[15,24,28,29]$.

\section{LIMITATIONS}

The major limitation of this study is the possibility for data entry errors from the source data. The study relied on secondary data over the years. However this is the best available data from the cytology unit that has been documented. Our inability to access background characteristic of the women limited the authors from establishing some association with the profiles of the women. Due to the fact that this study was informed by data from a single facility, making generalization of findings difficult. However this study would serve as a baseline for further research to compare all the regional and teaching hospitals to better understand the national prevalence of unsatisfactory Pap smear.

\section{CONCLUSIONS}

This study to the best of our knowledge, is the first ever study on unsatisfactory Pap smear in Ghana. 
The study identified scanty cellularity as the main cause of unsatisfactorily Pap smear. The 12-year prevalence compared to other studies is higher though incidence appears to be on the decline year on year. It is expected that the cytology unit adopts the liquid base preparation to get a monolayer smear and to lyse any blood obscurance to avoid unsatisfactory Pap smear.

The study has also provided evidence for the need to train staffs who take the Pap smears to increase their confidence in taking the smear due to high number of scanty cellularity's reports and lack of TZ component whilst encouraging the use of the recommendations that the right sampling tools be used. Computerized based archives should be implemented at the department since there was significant loss of reports and moreover the entire 2011 reports could not be found from archives.

\section{CONFLICTS OF INTEREST}

We declare no competing interest as the study did not get any funding from any organization.

\section{ACKNOWLEDGEMENTS}

We acknowledge the Department of Pathology, Cytology Unit, Korle-Bu Teaching Hospital, Accra-Ghana for allowing us to use access data from the unit for the conduct of this study.

\section{AUTHOR'S CONTRIBUTION}

MHA designed and conducted the study and contributed in the preparation and drafting of the manuscript. SCYA participated in data interpretation, contributed to the performing the statistical analysis and the manuscript drafting. Both authors read and approved the final manuscript.

\section{FUNDING}

The authors received no funding for this study.

\section{CONSENT FOR PUBLICATION}

Not Applicable.

\section{AVAILABILITY OF DATA AND MATERIALS}

The supporting data for this study is available on request but restrictions apply to the availability of the data. Data are however available from the authors upon reasonable request and with permission of the Korle-Bu Teaching hospital.

\section{ETHICS APPROVAL AND CONSENT TO PARTICIPATE}

Approval for this study was obtained from the College of Health Sciences, and Research Committee of the University of Ghana Medical School (UGMS).

\section{REFERENCES}

1. Demay, R.M. (1996) Diseases and Conditions of the Breast in: The Art and Science of Cytopathology: Aspiration Cytology. Chicago 856-869.

2. Saslow, D., Solomon, D., Lawson, H.W., Killackey, M., Kulasingam, S.L., Cain, J., et al. (2012) American Cancer Society, American Society for Colposcopy and Cervical Pathology, and American Society for Clinical Pathology Screening Guidelines for the Prevention and Early Detection of Cervical Cancer. CA: A Cancer Journal for Clinicians, 62, 147-172. https://doi.org/10.3322/caac.21139

3. Abdali, K., Soleimani, M., Khajehei, M., Tabatabaee, H.R., Komar, P.V. and Montazer, N.R. (2010) Comparison 
of Pap Smear Quality with Anatomical Spatula and Convenience (Spatula-Cytobrush) Methods: A Single Blind Clinical Trial. Asian Pacific Journal of Cancer Prevention, 11, 1769-1772.

4. Berland, L.L., Silverman, S.G., Gore, R.M., Mayo-Smith, W.W., Megibow, A.J., Yee, J., Brink, J.A., Baker, M.E., Federle, M.P., Foley, W.D. and Francis, I.R. (2010) Managing Incidental Findings on Abdominal CT: White Paper of the ACR Incidental Findings Committee. Journal of the American College of Radiology, 7, 754-773.

https://doi.org/10.1016/j.jacr.2010.06.013

5. Ebu, N.I., Mupepi, S.C., Siakwa, M.P. and Sampselle, C.M. (2015) Knowledge, Practice, and Barriers toward Cervical Cancer Screening in Elmina, Southern Ghana. International Journal of Women's Health, 7, 31-39. https://doi.org/10.2147/IJWH.S71797

6. Ghana Health Service (2013) Non-communicable Disease Control Programme: Strategies for Cervical Cancer Prevention in Ghana: Planning Meeting and Training of Health Staff for HPV Demo Vaccination in Ghana.

7. World Health Organization (2013) Comprehensive Cervical Cancer Prevention and Control: A Healthier Future for Girls and Women. http://apps.who.int/iris/bitstream/10665/78128/3/9789241505147_eng.pdf

8. Adanu, R.M. (2002) Cervical Cancer Knowledge and Screening in Accra, Ghana. Journal of Women's Health \& Gender-Based Medicine, 11, 487-488. https://doi.org/10.1089/152460902760277822

9. WHO/ICO Information Centre on HPV and Cervical Cancer (HPV Information Centre) (2010) Human Papillomavirus and Related Cancers in World. Summary Report 2010.

10. Conley, M. (2012) New Guidelines Discourage Yearly Pap Tests.

11. Fidda, N., Miron, J., Rodgers, W.H. and Rader, A. (2004) Impact of the New Bethesda System 2001 on Specimen Adequacy of Conventional Cervicovaginal Smears. Diagnostic Cytopathology, 30, 235-239. https://doi.org/10.1002/dc.10408

12. Agurto, I., Bishop, A., Sanchez, G., Betancourt, Z. and Robles, S. (2004) Perceived Barriers and Benefits to Cervical Cancer Screening in Latin America. Preventive Medicine, 39, 91-98. https://doi.org/10.1016/j.ypmed.2004.03.040

13. Davey, E., Barratt, A., Irwig, L., Chan, S.F., Macaskill, P., Mannes, P., et al. (2006) Effect of Study Design and Quality on Unsatisfactory Rates, Cytology Classifications, and Accuracy in Liquid-Based Versus Conventional Cervical Cytology: A Systematic Review. The Lancet, 367, 122-132.

https://doi.org/10.1016/S0140-6736(06)67961-0

14. Owens, C.L., Peterson, D., Kamineni, A., Buist, D.S., Weinmann, S., Ross, T.R., Williams, A.E., Stark, A., Adams, K.F. and Field, T.S. (2013) Effects of Transitioning from Conventional Methods to Liquid-Based Methods on Unsatisfactory Papanicolaou Tests: Results from a Multicenter US Study. Cancer Cytopathology, 121, 568-575. https://doi.org/10.1002/cncy.21309

15. Belinson, J.L., Pan, Q.-J., Biscotti, C., Wu, L.-Y., Pretorius, R.G., Li, L., et al. (2002) Primary Screening with Liquid-Based Cytology in an Unscreened Population in Rural China, with an Emphasis on Reprocessing Unsatisfactory Samples. Acta Cytologica, 46, 470-474. https://doi.org/10.1159/000326863

16. Nygård, J., Sauer, T., Nygård, M., Skare, G. and Thoresen, S.Ø. (2004) CIN 2/3 and Cervical Cancer in an Organised Screening Programme after an Unsatisfactory or a Normal Pap Smear: A Seven-Year Prospective Study of the Norwegian Population-Based Screening Programme. Journal of Medical Screening, 11, 70-76. https://doi.org/10.1258/096914104774061047

17. Ransdell, J.S., Davey, D.D. and Zaleski, S. (1997) Clinicopathologic Correlation of the Unsatisfactory Papanicolaou Smear. Cancer Cytopathology, 81, 139-143. https://doi.org/10.1002/(SICI)1097-0142(19970625)81:3<139::AID-CNCR2>3.0.CO;2-M

18. Mood, N.I. and Eftekhar, S.J. (2004) Clinicopathologic Correlation of the Unsatisfactory Papanicolaou Smear. 
Acta Medica Iranica, 42, 371-374.

19. Gupta, S., Sodhani, P., Sardana, S., Singh, V. and Sehgal, A. (2013) Clinical Determinants and Smear Characteristics of Unsatisfactory Conventional Cervicovaginal Smears. European Journal of Obstetrics \& Gynecology and Reproductive Biology, 168, 214-217. https://doi.org/10.1016/j.ejogrb.2013.01.010

20. McGaraghan, A. and Smith-McCune, K. (2000) Follow-Up of Unsatisfactory Papanicolaou Test Results. JAMA, 283, 1290-1291.

21. Lu, C.H., Chang, C.C., Ho, E.S., Chen, S.J., Lin, S.J., Fu, T.F. and Chang, M.C. (2010) Should Adequacy Criteria in Cervicovaginal Cytology Be Modified after Radiotherapy, Chemotherapy, or Hysterectomy? Cancer Cytopathology, 118, 474-481. https://doi.org/10.1002/cncy.20110

22. Castle, P.E., Bulten, J., Confortini, M., Klinkhamer, P., Pellegrini, A., Siebers, A.G., et al. (2010) Age-Specific Patterns of Unsatisfactory Results for Conventional Pap Smears and Liquid-Based Cytology: Data from Two Randomised Clinical Trials. BJOG: An International Journal of Obstetrics \& Gynaecology, 117, 1067-1073. https://doi.org/10.1111/j.1471-0528.2010.02650.x

23. Alsharif, M., McKeon, D.M., Gulbahce, H.E., Savik, K. and Pambuccian, S.E. (2009) Unsatisfactory SurePath Liquid-Based Papanicolaou Tests. Cancer Cytopathology, 117, 15-26. https://doi.org/10.1002/cncy.20009

24. Mirzamani, N., Chau, K., Rafael, O., Shergill, U., Sajjan, S., Sumskaya, I., et al. (2017) Quality Assessment and Improvement of "Unsatisfactory" Liquid-Based Cervicovaginal Papanicolaou Smears. Diagnostic Cytopathology, 45, 873-877. https://doi.org/10.1002/dc.23783

25. Katz, I.T. and Wright, A.A. (2006) Preventing Cervical Cancer in the Developing World. The New England Journal of Medicine, 354, 1110. https://doi.org/10.1056/NEJMp068031

26. Papillo, J.L., Zarka, M.A. and St. John, T.L. (1998) Evaluation of the ThinPrep Pap test in Clinical Practice. Acta Cytologica, 42, 203-208. https://doi.org/10.1159/000331547

27. Wright, T.C., Massad, L.S., Dunton, C.J., Spitzer, M., Wilkinson, E.J. and Solomon, D. (2007) 2006 Consensus Guidelines for the Management of Women with Abnormal Cervical Cancer Screening Tests. American Journal of Obstetrics and Gynecology, 197, 346-355. https://doi.org/10.1016/j.ajog.2007.07.047

28. Davey, D.D., Austin, R.M., Birdsong, G., Buck, H.W., Cox, J.T., Darragh, T.M., et al. (2002) ASCCP Patient Management Guidelines Pap Test Specimen Adequacy and Quality Indicators. American Journal of Clinical Pathology, 118, 714-718. https://doi.org/10.1309/6GBF-EGH8-WXDE-ANGX

29. Shortell, S.M., Bennett, C.L. and Byck, G.R. (1998) Assessing the Impact of Continuous Quality Improvement on Clinical Practice: What It Will Take to Accelerate Progress. The Milbank Quarterly, 76, 593-624.

https://doi.org/10.1111/1468-0009.00107 